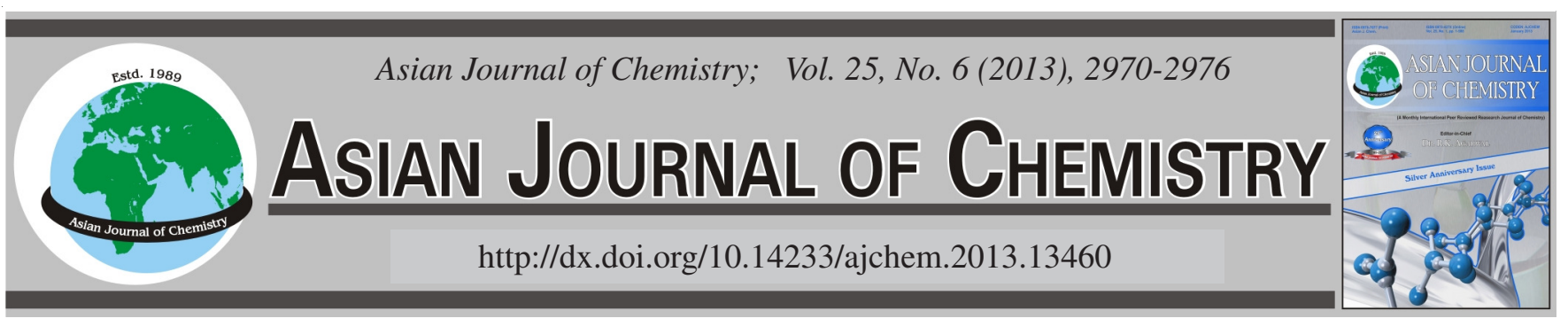

\title{
Effect of Exogenous Glutathione and Selenium on Cadmium-Induced Changes in Cadmium and Mineral Concentrations and Antioxidative Metabolism in Maize Seedlings
}

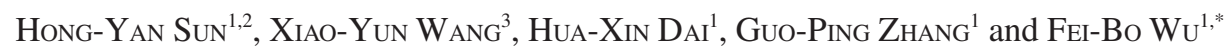

${ }^{1}$ Department of Agronomy, College of Agriculture and Biotechnology, Zijingang Campus, Zhejiang University, Hangzhou 310058, P.R. China ${ }^{2}$ College of Chemical and Biological Engineering, Taiyuan University of Science and Technology, Taiyuan 030024, P.R. China

${ }^{3}$ Institute of Shanxi Soil and Water Conservation, Taiyuan 030045, P.R. China

*Corresponding author: Tel: +86 13588715781; E-mail: wufeibo@zju.edu.cn

(Received: 16 January 2012;

Accepted: 5 December 2012)

AJC-12499

\begin{abstract}
A hydroponic experiment was carried out to study the modulation of exogenous reduced glutathione and selenium in antioxidant defense system and microelement uptake against cadmium-toxicity in maize seedlings. The results showed that $50 \mu \mathrm{M}$ cadmium increased accumulation of $\mathrm{H}_{2} \mathrm{O}_{2}$ and malondialdehyde but reduced plant height, root length, chlorophyll content (SPAD value) and biomass. Antioxidant enzyme activities of root/leaf peroxidase and leaf superoxide dismutase increased significantly under cadmium stress, while leaf catalase decreased significantly. Moreover, cadmium-stress reduced manganese concentrations both in shoots and roots. Significantly negative correlation was discovered between manganese and cadmium concentration in different plant organs. Addition of $2.5 \mu \mathrm{M}$ selenium or pretreated with $100 \mu \mathrm{M}$ glutathione for $24 \mathrm{~h}$ significantly alleviated cadmium-induced growth inhibition and dramatically diminished leaf $\mathrm{H}_{2} \mathrm{O}_{2}$ and root malondialdehyde accumulation. Se addition or glutathione pretreatment significantly decreased cadmium concentration in roots/shoots, increased root iron level, while glutathione reduced zinc uptake. Furthermore, GSH/Se counteracted cadmium-induced alterations of certain antioxidant enzymes, e.g. brought root/leaf peroxidase and leaf superoxide dismutase activities down towards to the control level, but elevated root ascorbate peroxidase activity. These data suggest that reduced cadmium concentration and diminished cadmium-induced $\mathrm{H}_{2} \mathrm{O}_{2}$ and malondialdehyde accumulation in plants could be principal protective mechanism for the exogenous glutathione/ selenium against cadmium toxicity.
\end{abstract}

Key Words: Antioxidative metabolism, Maize (Zea mays L.), Cadmium, Glutathione, Microelement, Selenium, Stress mitigation.

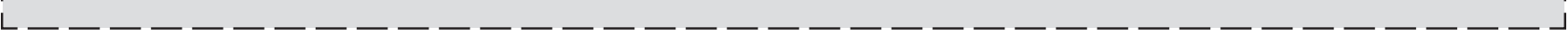

\section{INTRODUCTION}

Cadmium, one of the most aggressive heavy metals, is easily taken up by plants and translocated to above-ground tissues and then becomes a potential threat to human health via food chain ${ }^{1,2}$. Such a situation did occur in the 1950 s and 1960s in Japan where cadmium contamination of rice fields led to renal impairment and bone disease in exposed populations. In China, cadmium has posed a serious problem for food production and at least 13,330 ha of farmland involved in 11 provinces is contaminated by varying degrees of cadmium ${ }^{3}$. In brief, cadmium contamination in soil has turned into a potential agricultural and environmental issue worldwide ${ }^{4-6}$. Correspondingly it is urgently necessary to develop approaches to prevent its accumulation in plants so as to alleviate health risks associated with exposure to highly cadmium-contented food.

Reduced glutathione ( $\gamma$-Glu-Cys-Gly, GSH), a naturally occurring tripeptide, is a constituent of the cellular defense mechanism of the body against various exogenous as well as endogenously produced xenobiotics. Zhu et al. ${ }^{7}$ found that the increased capacity of glutathione (GSH) synthesis enhanced cadmium tolerance and accumulation in Indian mustard. Studies about the effect of intracellular GSH on heavy metal metabolism and toxicity indicate that GSH serves in bioreductive reactions as an important defense line against reactive oxygen species to protect cells from oxidative stress damage ${ }^{8}$ and modify metal toxicity by altering the rates of metal uptake and elimination ${ }^{9}$ and by chelating metal ions in cells ${ }^{10}$. Selenium was recognized as one of the indispensable essential trace elements for human and animal by the world health organization in 1973. Humans and animals require Se for the function of a number of Se-dependent enzymes, also known as selenoproteins for which a metabolic function has not yet been discovered. Gromer et al. ${ }^{11}$ suggested that the selective advantage of selenoenzymes is a broader range of substrates and a broader range of micro environmental conditions in which enzyme activity is possible. Concerning selenium- 
dependent enzymes, Se is an essential component of various enzymes involved in defense mechanism for biological membrane systems in animal bodies from various oxidative processes $^{12,13}$. Within this context, Se has been classified as an antioxidant and/or a heavy metal antagonist ${ }^{14}$, for providing protection from the toxic effects of heavy metals and other substances. The protective effect of Se against mercury toxicity in different biological systems of animals and aquatic organisms appears to have been the most studied ${ }^{15,16}$. Beneficial effects of Se in exposure to cadmium and silver have also been observed in mice and human ${ }^{17,18}$ although a full mechanistic explanation has not been realized. Gotsis ${ }^{19}$ reported that similar antagonism on the cell growth of the planktonic alga Dunaliella minuta Lerche was observed in combinations of $\mathrm{Se} / \mathrm{Hg}$ and $\mathrm{Se} / \mathrm{Cu}$ for cultures with and without prior exposure to either metal. However, so far there is little study on the effect of extracellular Se on responses to cadmium stress in plants. Thus a precise knowledge is required about the physiological processes responsible for the role of external Se on heavy metal stress, in order to test the hypothesis that external Se could act as a regulator or antioxidant intervention strategy in preventing oxidative stress in responses to cadmium stress and to get a better understanding of how plants adjust to an adverse environment.

The present study demonstrated at a physiological level the role of GSH and Se in promoting adaptive responses in antioxidant systems, mineral nutrients uptake and distribution of maize seedlings to cope with cadmium stress, where Se was administered along with the cadmium, but GSH was pretreatment for $24 \mathrm{~h}$ before cadmium stress. Hence, we conducted a hydroponic experiment to investigate effects of GSH and Se addition on the changes of mineral nutrients content, antioxidant defense system, $\mathrm{H}_{2} \mathrm{O}_{2}$ and lipid peroxidation level under cadmium stress.

\section{EXPERIMENTAL}

Plant material and experimental design: The hydroponic experiment was carried out on Huajiachi Campus, Zhejiang University, Hangzhou, China, using a common maize variety Nongda 108 . Healthy maize seeds were surface sterilized by soaking in $2 \% \mathrm{H}_{2} \mathrm{O}_{2}$ for $0.5 \mathrm{~h}$, rinsed with distilled water for seven times and then germinated in sterilized moist sand in an incubator at $20{ }^{\circ} \mathrm{C}$. At the $2^{\text {nd }}$ leaf stage ( 10 days old $)$, the uniform healthy plants were selected and transplanted to $5 \mathrm{~L}$ containers filled up 4.5-L basal nutrient solution $\left(\mathrm{mg} \mathrm{L}^{-1}\right)$ : $\left(\mathrm{NH}_{4}\right)_{2} \mathrm{SO}_{4}, 48.2 ; \mathrm{MgSO}_{4}, 65.9 ; \mathrm{K}_{2} \mathrm{SO}_{4}, 15.9 ; \mathrm{KNO}_{3}, 18.5$; $\mathrm{Ca}\left(\mathrm{NO}_{3}\right)_{2}, 59.9 ; \mathrm{KH}_{2} \mathrm{PO}_{4}, 24.8 ; \mathrm{Fe}$-citrate, $5 ; \mathrm{MnCl}_{2} \cdot 4 \mathrm{H}_{2} \mathrm{O}, 0.9$; $\mathrm{ZnSO}_{4} \cdot 7 \mathrm{H}_{2} \mathrm{O}, 0.11 ; \mathrm{CuSO}_{4} \cdot 5 \mathrm{H}_{2} \mathrm{O}, 0.04 ; \mathrm{HBO}_{3}, 2.9 ; \mathrm{H}_{2} \mathrm{MoO}_{4}$, 0.01 . The solution $\mathrm{pH}$ was adjusted to $5.8 \pm 0.1$ with $\mathrm{NaOH}$ or $\mathrm{HCl}$. The container was covered with a polystyrol-plate with 7 evenly spaced holes ( 1 plant per hole) and placed in a greenhouse. On the $7^{\text {th }}$ day after transplanting, cadmium (as $\mathrm{CdCl}_{2}$ ), $\mathrm{Se}$ (as $\mathrm{Na}_{2} \mathrm{SeO}_{3}$ ) and $\mathrm{GSH}$ were added to the corresponding containers to form 6 treatments: (1) control, basal nutrient solution (BNS); (2) Se, BNS + $2.5 \mu \mathrm{M} \mathrm{Se}$; (3) GSH, BNS + $100 \mu \mathrm{M}$ GSH, GSH was added on the $6^{\text {th }}$ day after transplanting and on the second day ( $7^{\text {th }}$ day after transplanting, i.e. after 24 $\mathrm{h}$ pretreated with $\mathrm{GSH}$ ) replaced with basal nutrient solution;
(4) cadmium, BNS + $50 \mu \mathrm{M} \mathrm{Cd}$; (5) $\mathrm{Cd}+\mathrm{Se}, \mathrm{BNS}+50 \mu \mathrm{M}$ $\mathrm{Cd}+2.5 \mu \mathrm{M} \mathrm{Se}$; and (6) $\mathrm{Cd}+\mathrm{GSH}, \mathrm{BNS}+24 \mathrm{~h}$ pretreated with $100 \mu \mathrm{M}$ GSH $+50 \mu \mathrm{M} \mathrm{Cd}, 100 \mu \mathrm{M}$ GSH was added on the day before cadmium treatment and on the second day replaced with $50 \mu \mathrm{M}$ cadmium. There were 3 replicates for each treatment. The nutrient solution was continuously aerated with pumps and renewed in 5 days interval.

Sampling and statistic analysis: Plant samples were collected after 5 days cadmium exposure. SPAD value of the $2^{\text {nd }}$ fully expanded leaves was determined using SPAD-502 chlorophyll meter. The fresh plant samples were directly used for the determination of antioxidative enzyme activities. Meanwhile, histochemistry staining of $\mathrm{H}_{2} \mathrm{O}_{2}$ in leaves was performed according to Romero-Puertas ${ }^{20}$. Each measurement was replicated 3 times. Statistical analyses were performed with data processing system statistical software package using ANOVA followed by the Duncan's multiple range test (SSR) to evaluate significant treatment effects at significance level of $\mathrm{P} \leq 0.05$.

Measurements of plant height, root length, biomass and microelements concentration: After 5 days treatment, plants were uprooted and separated into roots and leaves, the roots were soaked with $20 \mathrm{mM} \mathrm{Na} \mathrm{m}_{2}$ EDTA for $1 \mathrm{~h}$ to eliminate the ions on the surface and then rinsing in deionized water, plant height, root length and fresh weights were simultaneously measured, then dried at $80{ }^{\circ} \mathrm{C}$ and weighed. Dried shoots and roots were powdered and weighted, then ashed at $550{ }^{\circ} \mathrm{C}$ for $12 \mathrm{~h}$. The ash was digested with $5 \mathrm{~mL} 30 \% \mathrm{HNO}_{3}$ and then diluted using deionized water. Cadmium and other elements concentration were determined using a flame atomic absorption spectrometry (SHIMADZU AA-6300).

Histochemical staining of $\mathrm{H}_{2} \mathrm{O}_{2}$ and determination of lipid peroxidation: Histochemistry staining of $\mathrm{H}_{2} \mathrm{O}_{2}$ were performed as described by Romero-Puertas et al. ${ }^{20}$ with minor modification. Leaves were vacuum-infiltrated with $10 \mathrm{mM}$ potassium phosphate buffer (PBK, $\mathrm{pH}$ 6.5) containing $1 \%$ diaminobenzidine for $5 \mathrm{~min}$ and then incubated at $25^{\circ} \mathrm{C}$ for $12 \mathrm{~h}$ in dark. Leaves were illuminated until appearance of brown spots characteristic of the reaction of diaminobenzidine with $\mathrm{H}_{2} \mathrm{O}_{2}$.

The level of lipid peroxidation was quantified as malondialdehyde content according to $\mathrm{Wu}$ et $a$ al $^{21}$. Plant tissues were homogenized and extracted in $10 \mathrm{~mL}$ of $0.5 \%$ thiobarbituric acidmade in $5 \%$ trichloroacetic acid. Extract was heated at $95^{\circ} \mathrm{C}$ for $0.5 \mathrm{~h}$ and then quickly cooled with ice. After centrifugation at $10000 \mathrm{~g}$ for $10 \mathrm{~min}$, the absorbance of the supernatant was measured at $532 \mathrm{~nm}$. Correction of non-specific turbidity was made by subtracting the absorbance value taken at $600 \mathrm{~nm}$. The level of lipid peroxidation was calculated using an extinction coefficient of $155 \mathrm{mM} \mathrm{cm}^{-1}$.

Assay of enzyme activities: For the determination of enzyme activities, plant tissue was homogenized in $8 \mathrm{~mL} 50$ $\mathrm{mM}$ sodium phosphate buffer (PBS, $\mathrm{pH} 7.8$ ) using a prechilled mortar and pestle, then centrifuged at $10000 \mathrm{~g}$ for $15 \mathrm{~min}$ at $4{ }^{\circ} \mathrm{C}$. The supernatant was used for enzyme activity assay ${ }^{21}$. Superoxide dismutase, peroxidase and catalase activities were determined according to Zhang ${ }^{22}$. For the analysis of ascorbate peroxidase, ascorbate (AsA) was used as the substrate and the decrease in ascorbate concentration followed as a decline in 
optical density at $290 \mathrm{~nm}$ and the activity was calculated using the extinction coefficient $2.8\left(\mathrm{mM} \mathrm{cm}^{-1}\right)$ for ascorbate ${ }^{23}$.

\section{RESULTS AND DISCUSSION}

Exogenous Se and GSH pretreatment alleviate cadmium toxicity and reduce cadmium concentration in maize seedlings: As compared with the control, maize plants after $5 \mathrm{~d}$ exposure to $50 \mu \mathrm{M}$ cadmium significantly decreased plant height, root length and biomass and showed obvious symptoms of cadmium toxicity: leaf chlorosis and necrosis, brown roots and growth inhibition (Fig. 1). Pretreated with $100 \mu \mathrm{M}$ GSH for $24 \mathrm{~h}$ before $50 \mu \mathrm{M}$ cadmium stress $(\mathrm{Cd}+$ GSH) significantly alleviated cadmium-induced growth inhibition and the symptoms of chlorosis and necrosis on leaves. Glutathione pretreatment $(\mathrm{Cd}+\mathrm{GSH})$ suppressed cadmium uptake and leaf and root cadmium concentrations reduced by $61.1 \%$ and $29.0 \%$ when compared with those in cadmium alone treatment (Table-1). Similar alleviation trend was found in the $\mathrm{Cd}+\mathrm{Se}$ treatment (addition of $2.5 \mu \mathrm{M}$ Se in $50 \mu \mathrm{M}$ cadmium culture medium), i.e. after $5 \mathrm{~d} \mathrm{Cd}+$ Se treatment, plant height, root length and dry weight increased significantly by $14.3,36.8$ and $50.2 \%$ compared with cadmium alone treatment (Fig. 1) and cadmium concentration reduced by $39.9 \%$, $17.9 \%$ in leaves and roots respectively (Table-1). Furthermore, Se addition effectively inhibited the appearance of cadmium toxicity of chlorosis or necrosis in the leaves. No significant differences were observed between GSH pretreatment or Se addition (without cadmium) and control.

\begin{tabular}{lcccccc}
\multicolumn{7}{c}{ TABLE-1 } \\
EFFECT OF GSH PRETREATMENT AND SE SUPPLY \\
ON CADMIUM CONCENTRATIONS (MG KG ${ }^{-1}$ DW) \\
IN LEAVES AND ROOTS OF MAIZE SEEDLINGS \\
EXPOSED TO CADMIUM FOR 5 DAYS \\
\hline Control & Se & GSH & Cd & Cd + Se & Cd + GSH \\
\hline Shoot & $0.7 \mathrm{~d}$ & $0.4 \mathrm{~d}$ & $1.0 \mathrm{~d}$ & $183.2 \mathrm{a}$ & $110.1 \mathrm{~b}$ & $71.2 \mathrm{c}$ \\
Root & $2.9 \mathrm{~d}$ & $3.3 \mathrm{~d}$ & $2.8 \mathrm{~d}$ & $532.7 \mathrm{a}$ & $437.2 \mathrm{~b}$ & $378.3 \mathrm{c}$ \\
\hline
\end{tabular}

Means with the same letters are not significantly different at $\mathrm{P}=0.05$

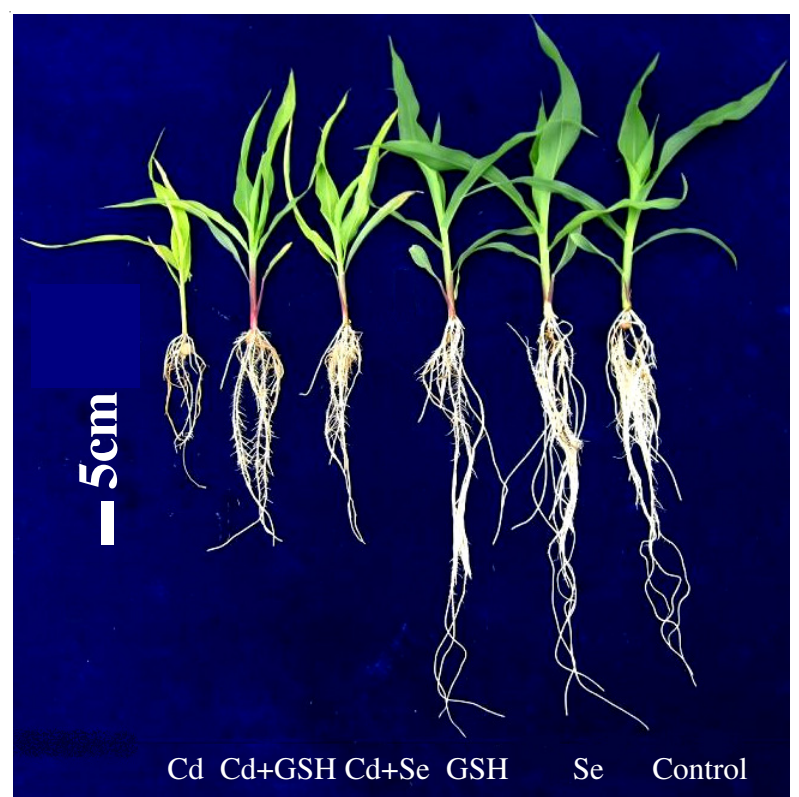

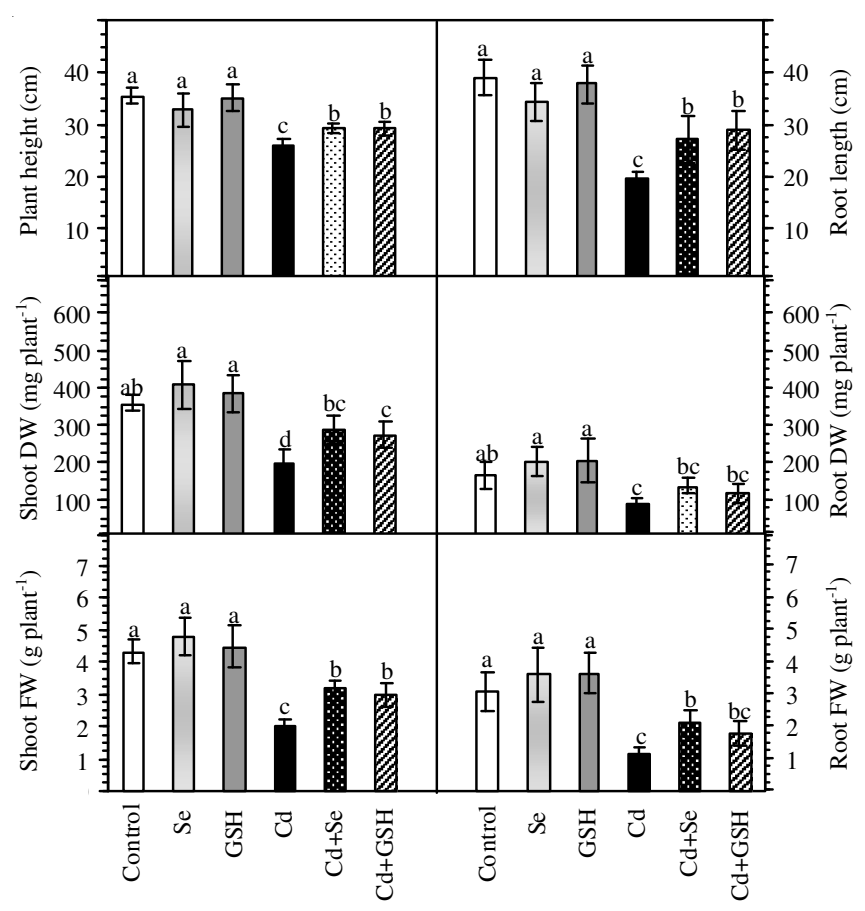

$\square \mathrm{Control} \square \mathrm{Se} \square \mathrm{GSH} \mathbf{C d} \mathrm{Cd}+\mathrm{Se} \boldsymbol{B} \mathrm{Cd}+\mathrm{GSH}$

Fig. 1. Effect of external glutathione (GSH) pretreatment and selenium (Se) supply on growth of maize seedlings exposed to $\mathrm{Cd}$ for 5 days. Control, $\mathrm{Cd}, \mathrm{Se}, \mathrm{GSH}, \mathrm{Cd}+\mathrm{GSH}$ and $\mathrm{Cd}+\mathrm{Se}$ correspond to basic nutrition solution (BNS), BNS $+50 \mu \mathrm{M} \mathrm{Cd}, \mathrm{BNS}+2.5 \mu \mathrm{M}$ Se, $\mathrm{BNS}+100 \mu \mathrm{M}$ GSH $(24 \mathrm{~h}$ pretreatment $)$ and $\mathrm{BNS}+50 \mu \mathrm{M} \mathrm{Cd}+$ $100 \mu \mathrm{M}$ GSH (24 h pretreatment before Cd exposure), BNS +50 $\mu \mathrm{M} \mathrm{Cd}+2.5 \mu \mathrm{M}$ Se respectively. Error bars represent SD values (n $=3$ ). Means with the same letters are not significantly different at $P$ $=0.05$

Determination of SPAD values of the fully expanded leaves of maize plants after $5 \mathrm{~d}$ cadmium exposure was shown in Fig. 2. The SPAD values of $50 \mu \mathrm{M}$ cadmium treatment greatly decreased by $60.8 \%$ relative to those of control, while addition of Se and GSH induced significant increase of 43.4 $\%$ and $52.5 \%$, respectively, over the cadmium alone treatment. Meanwhile no significant effects of Se and GSH alone (in the absence of cadmium) on SPAD value was observed when compared with the control.

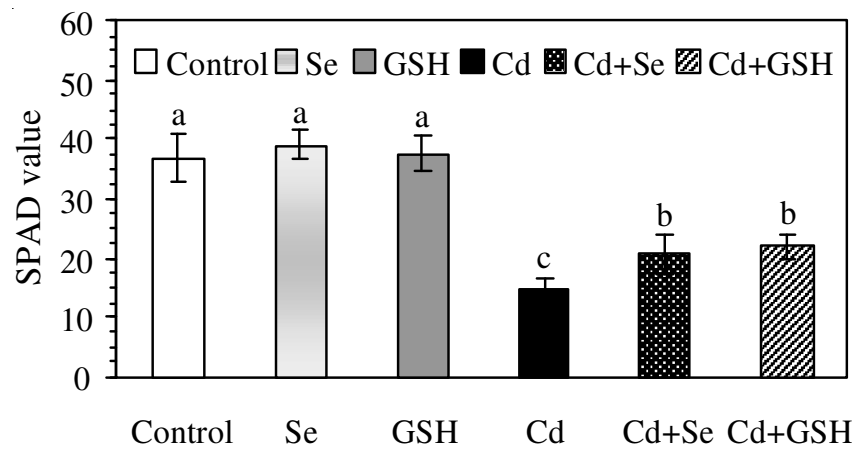

Fig. 2. Effect of GSH pretreatment and Se supply on SPAD value in leaves of maize seedlings exposed to $\mathrm{Cd}$ for 5 days. Control, Cd, Se, GSH, $\mathrm{Cd}+\mathrm{GSH}$ and $\mathrm{Cd}+\mathrm{Se}$ correspond to basic nutrition solution (BNS), $\mathrm{BNS}+50 \mu \mathrm{M} \mathrm{Cd}, \mathrm{BNS}+2.5 \mu \mathrm{M} \mathrm{Se}, \mathrm{BNS}+100 \mu \mathrm{M}$ GSH $(24 \mathrm{~h}$ pretreatment) and $\mathrm{BNS}+50 \mu \mathrm{M} \mathrm{Cd}+100 \mu \mathrm{M} \mathrm{GSH}(24 \mathrm{~h}$ pretreatment before Cd exposure), BNS $+50 \mu \mathrm{M} \mathrm{Cd}+2.5 \mu \mathrm{M}$ Se respectively. Error bars represent $\mathrm{SD}$ values $(\mathrm{n}=3)$. Means with the same letters are not significantly different at $\mathrm{P}=0.05$ 
GSH and Se alleviate cadmium-induced overproduction of $\mathrm{H}_{2} \mathrm{O}_{2}$ and lipid peroxidation: A significant increase in the accumulation of $\mathrm{H}_{2} \mathrm{O}_{2}$ (dark spots) was observed in the leaves of maize after 5 days cadmium exposure (Fig. 3C) and $\mathrm{H}_{2} \mathrm{O}_{2}$ scattered in the whole leaf. Glutathione pretreatment and Se addition in $50 \mu \mathrm{M}$ cadmium solution markedly diminished cadmium-induced $\mathrm{H}_{2} \mathrm{O}_{2}$ accumulation in leaves.

Cadmium stress increased malondialdehyde accumulation by $37.8 \%$ and $129.9 \%$ in the leaves and roots respectively compared with those in controls. Glutathione pretreatment decreased cadmium-induced malondialdehyde accumulation down towards control level (c.f. decreased by $36.2 \%$ and $62.8 \%$ in leaves and roots, respectively relative to cadmium alone treatment). Se addition effectively inhibited the cadmiuminduced malondialdehyde accumulation in roots (c.f. $53.5 \%$ lower than the cadmium alone treatment), but no significant effect on leaf malondialdehyde content. In addition, no significant change in malondialdehyde content was found in seedlings pretreated with GSH or Se addition (without cadmium) in comparison with controls (Fig. 3A).
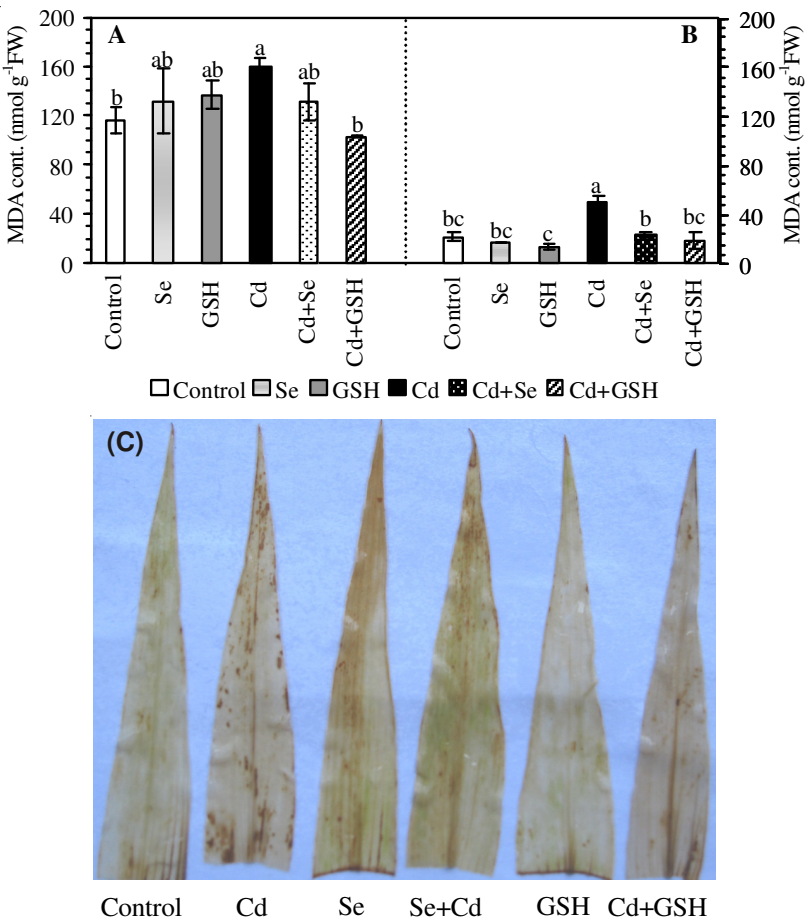

Fig. 3. Effect of GSH pretreatment and Se supply on MDA content in leaves (A) and roots (B) and histochemical detection of $\mathrm{H}_{2} \mathrm{O}_{2}$ in leaves (C) of maize seedlings exposed to $\mathrm{Cd}$ for 5 days. Control, $\mathrm{Cd}, \mathrm{Se}, \mathrm{GSH}$, $\mathrm{Cd}+\mathrm{GSH}$ and $\mathrm{Cd}+\mathrm{Se}$ correspond to basic nutrition solution (BNS), $\mathrm{BNS}+50 \mu \mathrm{M} \mathrm{Cd}, \mathrm{BNS}+2.5 \mu \mathrm{M}$ Se, BNS $+100 \mu \mathrm{M}$ GSH $(24 \mathrm{~h}$ pretreatment) and BNS $+50 \mu \mathrm{M} \mathrm{Cd}+100 \mu \mathrm{M}$ GSH $(24 \mathrm{~h}$ pretreatment before Cd exposure), BNS $+50 \mu \mathrm{M} \mathrm{Cd}+2.5 \mu \mathrm{M} \mathrm{Se}$ respectively. Error bars represent $\mathrm{SD}$ values $(\mathrm{n}=3)$. Means with the same letters are not significantly different at $\mathrm{P}=0.05$

Response of antioxidant enzymes to cadmium, Se and GSH addition: Maize plants treated with $50 \mu \mathrm{M}$ cadmium showed significant increase in peroxidase activity, being $327 \%$ in leaves and $85.4 \%$ in roots higher than those in the controls (Fig. 4). Both of GSH pretreatment and Se addition lowered cadmium-mediated increase of peroxidase activity in maize seedlings, giving readings $34.5 \%, 36.5 \%$ in leaves and $39.9 \%, 28.5 \%$ in roots lower than that of cadmium alone treatment.

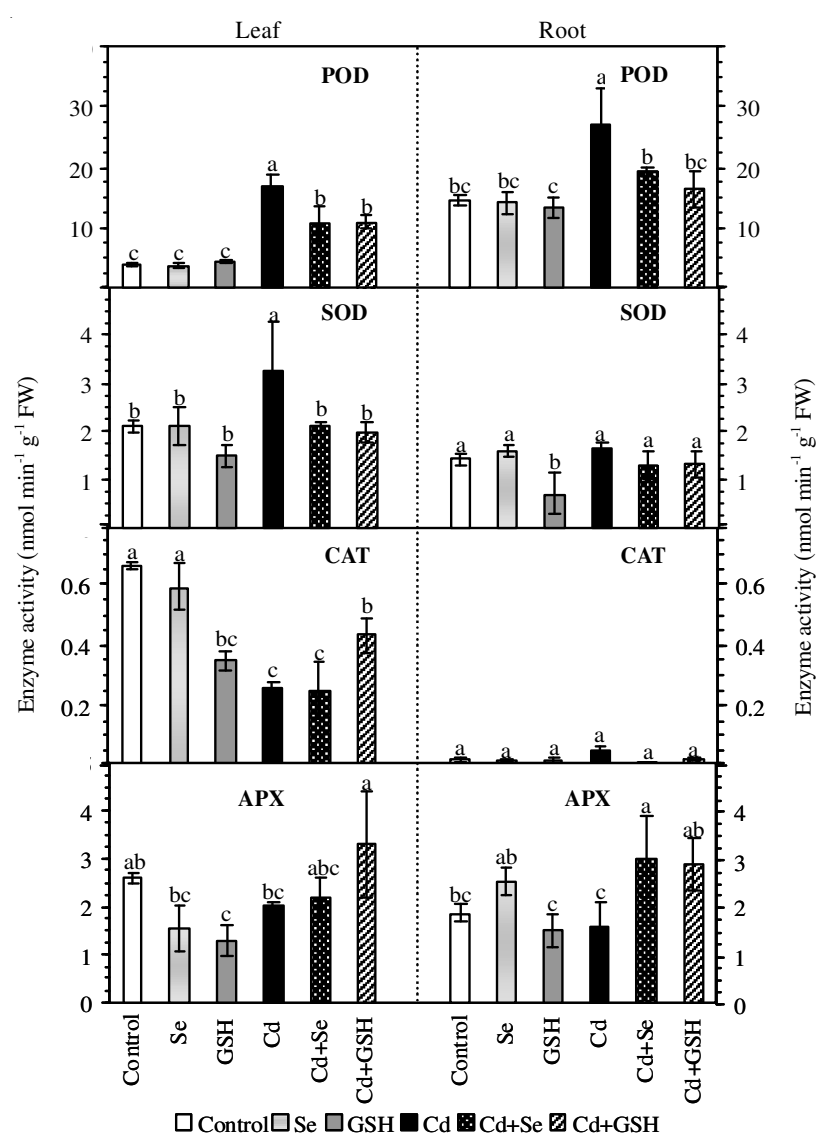

Fig. 4. Effect of GSH pretreatment and Se supply on MDA, POD, SOD, CAT and ascorbate peroxidase activities in leaves (left) and roots (right) of maize seedlings exposed to $\mathrm{Cd}$ for 5 days. Control, $\mathrm{Cd}$, $\mathrm{Se}, \mathrm{GSH}, \mathrm{Cd}+\mathrm{GSH}$ and $\mathrm{Cd}+\mathrm{Se}$ correspond to basic nutrition solution (BNS), BNS $+50 \mu \mathrm{M} \mathrm{Cd}$, BNS $+2.5 \mu \mathrm{M} \mathrm{Se}, \mathrm{BNS}+100$ $\mu \mathrm{M}$ GSH (24 h pretreatment) and BNS $+50 \mu \mathrm{M} \mathrm{Cd}+100 \mu \mathrm{M} \mathrm{GSH}$ (24 h pretreatment before $\mathrm{Cd}$ exposure), $\mathrm{BNS}+50 \mu \mathrm{M} \mathrm{Cd}+2.5$ $\mu \mathrm{M}$ Se respectively. Error bars represent SD values $(\mathrm{n}=3)$. Means with the same letters are not significantly different at $\mathrm{P}=0.05$

The effect of cadmium on superoxide dismutase activity showed significant difference in leaves and roots (Fig. 4). Cadmium stress induced substantial increase by $55.4 \%$ in leaf superoxide dismutase activity over the control, GSH pretreatment and Se addition noticeably brought superoxide dismutase activity back to the control level: markedly down-regulated cadmium-dependent marked increase and the activity almost returned to the control level. However, cadmium stress and $\mathrm{Cd}+\mathrm{GSH} / \mathrm{Cd}+\mathrm{Se}$ induced no significant effects on root superoxide dismutase activity compared with control (Fig. 4).

Cadmium stress resulted in a significant reduction in leaf catalase activity ( $49.2 \%$ reduction relative to control). Pretreatment of GSH greatly alleviated the decline in catalase activity caused by cadmium toxicity and the activity in $\mathrm{Cd}+$ GSH treatment increased by $44.2 \%$ when compared with cadmium treatment (Fig. 4). Addition of Se had no effect on catalase activity and there was no significant difference in root catalase activity among the six treatments.

The activity of ascorbate peroxidase in maize seedlings was shown in Fig. 4. No significant difference in ascorbate 
peroxidase activity was observed between cadmium alone treatment and control. Glutathione pretreatment alone significantly decreased leaf ascorbate peroxidase activity. $\mathrm{Cd}+\mathrm{GSH}$ markedly increased ascorbate peroxidase activity in leaves/ roots, while $\mathrm{Cd}+\mathrm{Se}$ only improved root ascorbate peroxidase activity compared with cadmium alone treatment and even higher than control.

Effects of GSH pretreatment and Se addition on micronutrient concentration under cadmium stress in maize seedlings: Effects of GSH pretreatment and Se addition on cadmium concentration were shown in Table-1. Addition of $\mathrm{Se}(\mathrm{Cd}+\mathrm{Se})$ significantly decreased cadmium levels by 39.9 $\%$ and $17.9 \%$ in leaves and roots, respectively, compared with cadmium alone treatment. Similar decreasing trend was found in the Cd + GSH treatment: decreased by $61.1 \%$ and $29.0 \%$ in leaves and in roots respectively. The trends of $\mathrm{Cd}+\mathrm{Se}$ and $\mathrm{Cd}+\mathrm{GSH}$ lowered cadmium concentration was much more pronounced in leaves than that in roots (Table-1).

Concerning $\mathrm{Zn}, \mathrm{Fe}, \mathrm{Cu}$ and $\mathrm{Mn}$ concentrations (Fig. 5), cadmium stress markedly reduced leaf/root $\mathrm{Mn}$ and root $\mathrm{Fe}$ concentrations $(58.6,91.2$ and $23.1 \%$ reduction relative to the control), while no significantly effect on $\mathrm{Cu}, \mathrm{Zn}$ and leaf Fe concentrations.

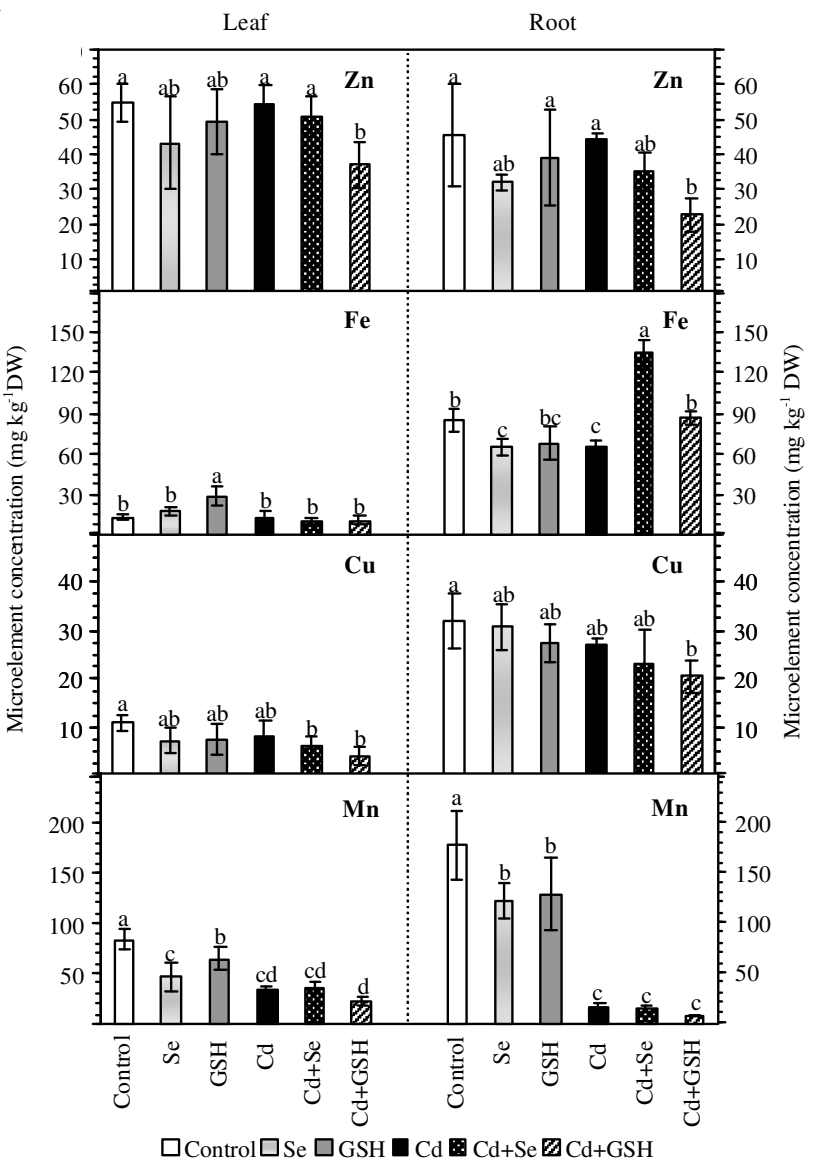

Fig. 5. Effect of GSH pretreatment and Se supply on micronutrient element concentrations in leaves (left) and roots (right) of maize seedlings exposed to Cd for 5 days. Control, $\mathrm{Cd}, \mathrm{Se}, \mathrm{GSH}, \mathrm{Cd}+\mathrm{GSH}$ and $\mathrm{Cd}$ + Se correspond to basic nutrition solution (BNS), BNS $+50 \mu \mathrm{M}$ $\mathrm{Cd}, \mathrm{BNS}+2.5 \mu \mathrm{M}$ Se, BNS $+100 \mu \mathrm{M}$ GSH $(24 \mathrm{~h}$ pretreatment $)$ and $\mathrm{BNS}+50 \mu \mathrm{M} \mathrm{Cd}+100 \mu \mathrm{M} \mathrm{GSH}(24$ h pretreatment before $\mathrm{Cd}$ exposure), BNS $+50 \mu \mathrm{M} \mathrm{Cd}+2.5 \mu \mathrm{M}$ Se respectively. Error bars represent $\mathrm{SD}$ values $(n=3)$. Means with the same letters are not significantly different at $\mathrm{P}=0.05$
Glutathione pretreatment $(\mathrm{Cd}+\mathrm{GSH})$ decreased $\mathrm{Zn}$ concentration by $31.9 \%$ in leaves and $48.4 \%$ in roots respectively compared with cadmium alone treatment, while no significant difference was found between $\mathrm{Cd}+\mathrm{Se}$ and cadmium alone treatments. $\mathrm{Cd}+\mathrm{GSH} / \mathrm{Cd}+\mathrm{Se}$ significantly increased cadmium-induced reduction in root Fe levels $(33.8 \%, 106.4 \%$ higher than cadmium alone treatment), but no effect on leaf $\mathrm{Fe}$ and leaf/root $\mathrm{Mn}$ and $\mathrm{Cu}$ levels.

Correlations between cadmium and four microelements: The relationship between cadmium and $\mathrm{Fe}, \mathrm{Zn}, \mathrm{Cu}$, Mn was shown in Table-2. Significantly negative correlation was discovered between manganese and cadmium concentration in the different plant organs. The significant positive correlation occurred between $\mathrm{Zn}, \mathrm{Mn}$ and $\mathrm{Cu}$ both in leaves and in roots. In addition, $\mathrm{Cu}, \mathrm{Fe}$ was negative correlated with cadmium, but did not reach the significant level.

Cadmium principally occurs in the human diet as a result of its uptake and accumulation from soil by crop plants, although the whole pathway of cadmium transfer into the food chain is also involved in input from atmosphere, water and aquatic life. Moreover, cadmium contamination is a nonreversible accumulation process, with the estimated half-life in soil varying between 15 and 1100 years ${ }^{24}$ and high plantsoil mobility to be easily accumulated in plant tissues, while high accumulation of cadmium in plants not only deteriorates crop yield and quality, but also gives rise to a threat on human health via food chain. Excess cadmium in the diet results in damage to kidney tubules, rhinitis, emphysema as well as other chronic disorders. Correspondingly it is urgently necessary to develop approaches to prevent the accumulation of cadmium in plants so as to alleviate health risks associated with exposure to highly cadmium-contaminated food. Considering large-scale medium/slightly contaminated farmlands such approaches as the application of chemical regulators to alleviate cadmium toxicity and simultaneously reduce plant cadmium uptake would be a cost-effective and practically acceptable strategy for full utilization of natural resource and safe food production. In our previous work, we described that exogenous GSH significantly alleviated cadmium-toxicity in barley seedlings and decreased cadmium concentrations in all plant tissues ${ }^{8}$. The present study demonstrated that addition of $2.5 \mu \mathrm{M} \mathrm{Se}(\mathrm{Cd}+\mathrm{Se}$ treatment) or pretreated with $100 \mu \mathrm{M}$ GSH for $24 \mathrm{~h}(\mathrm{Cd}+$ GSH) significantly alleviated cadmium-induced growth inhibition, diminished leaf $\mathrm{H}_{2} \mathrm{O}_{2}$ and root malondialdehyde accumulation and dramatically reduced shoot and root cadmium concentration (Table-1). The results suggested a practical potential for exogenous GSH/Se application as an intervention strategy in mitigating cadmium stress and reducing cadmium uptake and translocation in maize plants.

The interactions of cadmium and metal nutrients have been reported in some upland crops, such as wheat ${ }^{25}$, barley $^{26,6}$, tomato $^{27}$ and soybean ${ }^{28}$. However, the interactions between cadmium and other nutrients are complicated and quite different with species. Our previous study found significantly negative correlation between $\mathrm{Zn}, \mathrm{Cu}$, or $\mathrm{Mn}$ concentration and cadmium concentration in barley plants ${ }^{6}$. The same effects on Mn were observed in the present experiment. Maize plants exposed to $50 \mu \mathrm{M}$ cadmium significantly reduced $\mathrm{Mn}$ concentration by $58.6 \%, 91.2 \%$ in leaves and roots, respectively, compared 


\begin{tabular}{|c|c|c|c|c|c|c|c|c|c|c|}
\hline & \multicolumn{10}{|c|}{$\begin{array}{l}\text { TABLE-2 } \\
\text { CORRELATIONS BETWEEN CADMIUM AND FOUR MICRONUTRIENT ELEMENTS CONCENTRATIONS } \\
\text { IN LEAVES AND ROOTS FOR MAIZE SEEDLINGS EXPOSED TO CADMIUM FOR } 5 \text { DAYS }\end{array}$} \\
\hline & \multicolumn{5}{|c|}{ Shoot mental concentration (SMC) } & \multicolumn{5}{|c|}{ Root mental concentration (RMC) } \\
\hline & $\mathrm{Cd}$ & $\mathrm{Zn}$ & $\mathrm{Fe}$ & $\mathrm{Cu}$ & $\mathrm{Mn}$ & $\mathrm{Cd}$ & $\mathrm{Zn}$ & $\mathrm{Fe}$ & $\mathrm{Cu}$ & $\mathrm{Mn}$ \\
\hline \multicolumn{11}{|l|}{ SMC } \\
\hline $\mathrm{Cd}$ & 1.00 & 0.24 & -0.54 & -0.26 & -0.65 & $0.96^{* *}$ & 0.09 & 0.23 & -0.48 & $-0.83^{*}$ \\
\hline $\mathrm{Zn}$ & & 1.00 & 0.06 & $0.81 *$ & 0.55 & 0.02 & $0.96 * *$ & 0.06 & 0.51 & 0.27 \\
\hline $\mathrm{Fe}$ & & & 1.00 & 0.17 & 0.46 & -0.64 & 0.18 & -0.49 & 0.32 & 0.52 \\
\hline $\mathrm{Cu}$ & & & & 1.00 & $0.87 *$ & -0.48 & $0.90^{* *}$ & -0.24 & $0.87 * *$ & 0.74 \\
\hline $\mathrm{Mn}$ & & & & & 1.00 & $-0.78^{*}$ & 0.67 & -0.23 & $0.80 *$ & $0.93 * *$ \\
\hline \multicolumn{11}{|l|}{ RMC } \\
\hline $\mathrm{Cd}$ & & & & & & 1.00 & -0.16 & 0.39 & -0.70 & $-0.94 * *$ \\
\hline $\mathrm{Zn}$ & & & & & & & 1.00 & -0.18 & 0.68 & 0.45 \\
\hline $\mathrm{Fe}$ & & & & & & & & 1.00 & -0.50 & -0.43 \\
\hline $\mathrm{Cu}$ & & & & & & & & & 1.00 & $0.85^{*}$ \\
\hline $\mathrm{Mn}$ & & & & & & & & & & 1.00 \\
\hline
\end{tabular}

with control (Fig. 5). Significantly negative correlation was discovered between $\mathrm{Mn}$ and cadmium concentration in different plant organs (Table-2). This result indicate that cadmium may compete with manganese transporter systems and keeping rate of manganese uptake steady may be important for cadmium tolerance in maize. Therefore, excessive cadmium accumulation would affect the rate of manganese uptake and distribution in the plants and consequently would be responsible for manganese deficiencies/mineral imbalance and depression of the plant growth. The work of Wang and his coworkers showed increased Fe uptake under cadmium stress in maize ${ }^{29}$. Liu et al. ${ }^{30}$ found significant correlation on root content between cadmium and $\mathrm{Cu}$ or $\mathrm{Fe}$ in rice cultivars. However, some other researches related to changes of $\mathrm{Fe}$ concentrations under cadmium stress, showed not significant correlation between these two metals ${ }^{31}$. In the present study, cadmium significantly reduced root $\mathrm{Fe}$ concentration but no effect on shoot concentration. Addition of Se or pretreatment with GSH elevated root $\mathrm{Fe}$ concentration in $50 \mu \mathrm{M}$ cadmium present solution. Thus, elevated uptake of Fe may be one of the mitigatory effect of external GSH/Se in maize plants. In addition, significantly positive correlations between $\mathrm{Zn}, \mathrm{Cu}$ and $\mathrm{Mn}$ were observed in this study. The results highlight the possibility of developing maize cultivars/lines with moderately high $\mathrm{Mn}, \mathrm{Cu}$ and $\mathrm{Fe}$ levels.

\section{Conclusion}

The present study demonstrated that cadmium-induced oxidative stress being visualized by the increased $\mathrm{H}_{2} \mathrm{O}_{2}$ and malondialdehyde accumulation in leaves and roots of maize plants exposed to $50 \mu \mathrm{M}$ cadmium over the control (Fig. 3), in agreement with the results reported by Chen $e t a l .{ }^{8}$, also by Hegedüs et al. $^{32}$, May and Leaver ${ }^{33}$ and Zhang et al..$^{34}$. To protect oxidative stress, plants evolutionally developed enzymatic and non-enzymatic reactive oxygen species scavenging systems to maintain cellular redox state ${ }^{35}$. In this study, as an adaptive mechanism peroxidase and superoxide dismutase activities were correspondingly induced to cope with reactive oxygen species (Fig. 4), while leaf catalase activity decreased in the plants exposed to $50 \mu \mathrm{M}$ cadmium. Selenium addition or GSH pretreatment successfully decreased cadmium-induced reactive oxygen species and malondialdehyde accumulation, significantly counteracted cadmium-induced alterations of certain antioxidant enzymes, e.g. brought root/leaf peroxidase and leaf superoxide dismutase activities down towards to the control level, but elevated root ascorbate peroxidase activity. Meanwhile, elevated catalase and ascorbate peroxidase activities in leaves were also observed in the plants under $\mathrm{Cd}$ + GSH treatment. These results provide evidence that GSH/ Se facilitates substantial protection against oxidative injury in responses to cadmium stress. Taken together, reduced cadmium uptake and translocation and the protection against oxidative injury could be principal protective mechanism for the exogenous GSH/Se in alleviation cadmium toxicity. The results also suggested a practical potential for GSH/Se as a potent antioxidant in plants and that its action may, at least in part, be explained by their ability to directly and indirectly scavenge reactive oxygen species.

\section{ACKNOWLEDGEMENTS}

This project was funded by National Natural Science Foundation of China (30571097) and the Key Research Foundation of Zhejiang Bureau of Science and Technology (2009C12050).

\section{REFERENCES}

1. J. Dong, W.H. Mao, G.P. Zhang, F.B. Wu and Y. Cai, Plant Soil Environ., 53, 193 (2007).

2. K. Smeets, J. Ruytinx, B. Semane, F.V. Belleghem, T. Remans, S.V. Sanden, J. Vangronsveld and A. Cuypers, Environ. Exp. Bot., 63, 1 (2008).

3. J.B. Zhang and W.N. Huang, Acta Ecol. Sin., 20, 514 (2000).

4. F.Y. Wang, C.S. Zhang and X.F. Xu, Asian J. Chem., 24, 657 (2012).

5. F. Chen, J. Dong, F. Wang, F.B. Wu, G.P. Zhang, G.M. Li, Z.F. Chen, J. Chen and K. Wei, Chemosphere, 67, 2082 (2007).

6. F.B. Wu, G.P. Zhang and J.S. Yu, Commun. Soil Sci. Plant Nutr., 34, 2003 (2003).

7. Y.L. Zhu, E.A.H. Pilon-smits, A.S. Tarun, S.U. Weber, L. Jouanin, N. Terry, Plant Physiol., 121, 1169 (1999).

8. F. Chen, F. Wang, F.B. Wu, W.H. Mao, G.P. Zhang and M.X. Zhou, Plant Physiol. Biochem., 48, 663 (2010).

9. Y.J. Kang and M.D. Enger, Cell Biol. Toxicol., 3, 347 (1987).

10. P.L. Lima, J.C. Benassi, R.C. Pedrosa, J.D. Magro, T.B. Oliveira and D.W. Filho, Arch. Environ. Contam. Toxicol., 50, 23 (2006).

11. S. Gromer, L. Johansson, H. Bauer, L.D. Arscott, S. Rauch, D.P. Ballou, C.H. Williams Jr., R.H. Schirmer and E.S. Arnér, Proc. Nat. Acad. Sci. USA, 100, 12618 (2003).

12. L.R. McDowell, Minerals in Animal and Human Nutrition, University of Florida, Gainesville, edn. 2, pp. 235-276 (2003). 
13. E.J. Underwood and N.F. Suttle, The Mineral Nutrition of Livestock, Midlothian, UK, edn. 3, pp. 283-392 (1999).

14. K.O. Cafferky, D.D. Richardson and J.A. Caruso, Spectroscopy, 21, 18 (2006).

15. K.T. Suzuki and Y. Ogra, Phosphorus Silicon Sulfur Rel. Elem., 171, 135 (2001)

16. S. Mounicou, M. Shah, J. Meija, J.A. Caruso, A.P. Vonderheide and J. Shann, J. Anal. Atom Spectrom., 21, 404 (2006).

17. L.B. Nehru and M.P. Bansal, J. Appl. Toxicol., 17, 81 (1997).

18. G. Drasch, J. Schopfer and G.N. Schrauzer, Biol. Trace Elem. Res., 103, 103 (2005).

19. O. Gotsis, Mar Biol., 71, 217 (1982)

20. M.C. Romero-Puertas, M. Rodriguez-Serrano, F.J. Corpas, M. Gomez, L.A. Del Rio and L.M. Sandalio, Plant Cell Environ., 27, 1122 (2004).

21. F.B. Wu, G.P. Zhang and P. Dominy, Environ, Exp, Bot., 50, 67 (2003).

22. X.Z. Zhang, Research Methodology of Crop Physiology, Agriculture Press, Beijing, pp. 208-211 (1992)

23. H.H. Ruan, W.B. Shen, M.B. Ye and L.L. Xu, Chinese Sci. Bull., 46, 1993 (2001)
24. A. Kabata-Pendias and H. Pendias, Trace Elements in Soils and Plants, CRC Press Inc. Boca Raton, Florida, edn. 3 (2001).

25. G.P. Zhang, M. Fukami and H. Sekimoto, Field Crops. Res., 77, 93 (2002).

26. F.B. Wu, G.P. Zhang, Bull. Environ. Contam. Toxicol., 69, 219 (2002).

27. G.C. Smith and E.G. Brennan, Phytopathology, 73, 879 (1983).

28. D.A. Cataldo, T.R. Garland and R.E. Wildung, Plant Physiol., 73, 844 (1983).

29. M. Wang, J.H. Zou, X.C. Duan, W.S. Jiang and D.H. Liu, Bioresour. Technol., 98, 82 (2007)

30. J.G. Liu, J.S. Liang, K.Q. Li, Z.J. Zhang, B.Y. Yu, X.L. Lu, J.C. Yang and Q.S. Zhu, Chemosphere, 52, 1467 (2003).

31. A. Chaoui, M.H. Ghorbal and E.E. Ferjani, Plant Sci., 126, 21 (1997).

32. A. Hegedüs, S. Erdei and G. Horváth, Plant Sci., 160, 1085 (2001).

33. M.J. May and C.J. Leaver, Plant Physiol., 103, 621 (1993).

34. H. Zhang, W. Xu, J. Guo, Z. He and M. Ma, Plant Sci., 169, 1059 (2005).

35. R.D. Baisak, P.B.B. Rana and M.K. Acharya, Plant Cell Physiol., 35, 489 (1994) 